\title{
HIVIAIDS Knowledge and Gender Differences among High School Students in Nairobi, Kenya
}

\author{
Tuntufye S Mwamwenda \\ Nelson Mandela Metropolitan University, 50 Holzner Road, Pinetown 3610, South Africa \\ tsmwamwenda@yahoo.com
}

\section{Doi:10.5901/mjss.2014.v5n27p645}

\begin{abstract}
The objective of this study was to assess the HIVIAIDS knowledge among high school boys and girls in Nairobi, Kenya. The sample of the study comprised 69 female and 88 male participants drawn from two randomly identified high schools in Nairobi. Participants were administered an HIVIAIDS questionnaire. The method of data analysis comprised frequencies, percentage and chi-square. The results showed that there were three categories in the findings. In the first category for some questions, there were no gender differences. In second category, there were gender differences in favour of male participants, while in the third category girls were more knowledgeable about HIVIAIDS than boys. In conclusion, it was advocated that, educating, motivating, persuading and enabling should be the chief cornerstones of HIVIAIDS public education campaigns. This will go a long way in equipping adolescents to protect themselves against the scourge of HIVIAIDS
\end{abstract}

Keywords: HIVIAIDS, gender differences, public education campaigns, Kenya adolescents, females and HIVIAIDS, secondary school.

\section{Introduction}

In many parts of the world, HIVIAIDS has attained the status of pandemic, which means large areas are affected, and HIVIAIDS continues spreading (Kibombo, Neema \& Ahmed, 2007; Ebeniro 2010; Janckie, Garegae \& Tsheko, 2011). In this regard, Facents (2001) warns that, whereas there has been a visible decline of the rate of HIV to AIDS, there has been an increase in the contraction of HIVIAIDS. Since there is no known cure for HIVIAIDS, though manageable, prevention remains the only surety for combating it.

In Kenya, HIV is declared to be the greatest challenge Kenyans are confronted with (Gakahu \& Kaguta 2011; National AIDS Control Council (NACC) \& National AIDS/STI Control Programme (NASCP)). Despite concerted and enormous effort to bring it under control, the epidemic continues being a threat to lives of millions of Kenyans. By December 2011, 1.6 million Kenyans were living with HIVIAIDS, and it is predicted the number is likely to increase rather than decrease in the foreseeable future (NACC \& NASCOP 2012). Of the 1.6 Kenyans living with HIVIAIDS, 59\% are women. The number of HIVIAIDS infected Kenyans (1.6 millions) is higher than what would be considered reasonable. For example, in 2011 the increase in infection stood at 104,137. Since HIVIAIDS was detected in Kenya in 1984, 1.7 million Kenyans have lost their lives (NACC \& NASCOP 2012).

Given the challenge of HIVIAIDS that adolescents encounter in their present and future life experience, it is vital that their awareness of the risks associated with sexual behaviour is made clear, and correspondingly the transfer of such awareness to real life experience is expected (Mwamwenda 2014). Njogu \& Martin (2003) and Kabiru \& Orpinas (2009a) advance the argument that in view of the high rate of HIV in Sub-Saharan Africa creates the environment for the quest for understanding forces that influence adolescents' sexual behaviour.

According to the African Population Health Research Center (2009) in Kenya, adolescence is an important period in human development, as a person reaches sexual maturity manifest in sexual engagement, thus encountering the possibility of contracting sexually transmitted diseases such as HIV. This is summarised in the assertion of Kamala \& Aboud (2006) who conclude that the adolescents are identified as reproductive category in human development is more at HIVIAIDS risk than other human beings. For this reason and more, it deserves more attention in combating infection, and transmission of HIVI AIDS.

The preceding narration partly served as a backdrop for the motivation to undertake an investigation of gender differences in HIVIAIDS knowledge among high school adolescents in Kenya. Njogu and Martin (2003) carried out a study of Kenyan adolescents to determine the relationship between knowledge about HIVIAIDS, perceived personal risk and application of safe sex practices. The results showed no transfer of learning in terms of their sex practices. Along the 
same line, both Kabiru and Orpinas (2009a) made a study of 8,556 male and female adolescent high school students in Nairobi, Kenya. In conclusion, they proposed that adolescents would benefit from sex education programmes alerting them to the factors that predispose them to HIVIAIDS transmisssion.

Erikson, Sonasson \& Isacsson (1997) report on a comparative study of 326 Kenyan and146 Swedish teenagers' HIVIAIDS knowledge and information, with the objective of determining racial differences and similarities in knowledge and their sources of information. The level of knowledge was good, though it differed according to the various questions answered. It is underscored that, despite the high knowledge, the spread of HIVIAIDS remained unaffected. Therefore, this calls for better strategies that focus on life styles changes. For this to be realized, the health care system, the education system, civil and voluntary information system have an important role to play.

The African Population and Health Research Center (2009) carried out a huge study of 3,612 adolescents aged 12-25 years, randomly drawn from three types of secondary schools in Nairobi: single-gender, co-educational and both boarding and day secondary schools. Their knowledge of prevention of transmission was high, but was not applied to their sexual behaviour practices, though a small number of them made transfer of such knowledge. For example, one fifth of sexually active boys used condom regularly; one third of the boys used condom irregularly, while others did not see the need for the use of condoms. It was therefore concluded that, there was need for comprehensive sexuality education programmes, which equip adolescents to protect themselves against the scourge of HIVIAIDS.

Njogu and Martin (2003) investigated the persisting gap between HIVIAIDS and knowledge and prevention among Kenyan youth. The results showed that, there was an increase in the use of contraceptives, including the use of condoms which were less frequently made use of. Both boys and girls knew how HIV is transmitted, and identified AIDS as instrumental in terminating one's life. Most participants considered themselves less vulnerable to contracting HIVIAIDS, when they engaged in sexual activity. This led to the conclusion that what is being advocated is: educating, motivating, persuading and enabling should be the chief cornerstones of HIVIAIDS campaigns.

Kabiru and Orpinas (2009a) propose that, given the high rate of HIV infection in Sub-Saharan Africa cerates the environment to the quest for understanding the forces that influence adolescents' sexual behaviour. Therefore they carried out a study of 3,556 male and female adolescent high school students in Nairobi, Kenya. Close to $50 \%$ of the males and $11 \%$ of the females reported being sexually active. The study concluded that adolescents would benefit from sex education programmes alerting them to the factors that predispose them to HIVIAIDS.

In a similar investigation, Kabiru and Orpinas (2009b) made a study of correlates of condom use among 931 sexually active male high school students in Nairobi and their knowledge of HIVIAIDS. Of the total number of participants, $50 \%$ reported to be users of condoms. Their knowledge of HIVIAIDS was not significantly different. All participants were of the view that chances of contracting HIVIAIDS was rather low if not $n$ non-existent.

Mwamwenda (2014) investigated the HIVIAIDS knowledge among high school adolescents in Kenya. As a subsidiary objective, the investigation sought to determine whether there was transfer of knowledge in terms of the relationship between participants and their sexual behaviour. The results showed that adolescent high school students had a high level of HIVIAIDS knowledge and that such knowledge had transfer to their sexual relationship as boys and girls. Mwendwa (2013) points out that more women than men are vulnerable to HIV?AIDS on account of their physiological composition. This is in addition to other factors comprising: social, legal, economic and cultural disadvantages. Mwendwa (2013) further argues that Kenyan girls and women are less HIVIAIDS knowledgeable than their counterparts in reference to boys and men. Moreover, girls and women are less inclined to the use of preventive measures, such as the use of condom.

Similarly, the National AIDS Control Council and the National AIDS/STI Control Programme (2012) clearly state: "On the average, Kenyan women and girls are less knowledgeable than males regarding HIV. HIV represents a continuing threat to young people in Kenya. Among 20-24-year-olds, more than 1 in 25 (4.2\%) are already infected when they enter young adulthood" (p24). The level of risk is even much higher among young women and girls. In fact, the probability of contracting HIVIAIDS is four times that of men (Ibid).

Adegoke, Fife, \& Corneille (2011) investigated adolescents' knowledge, attitudes, beliefs regarding HIVIAIDS based on age, gender, and parents' education status. The sample comprised 1902 respondents whose age ranged from 12-20 years, their level of HIVIAIDS knowledge related to the existence, modes of transmission and vulnerability was deemed good. While this was so, there were misconceptions patterning to the existence of cure of HIVIAIDS.

In terms of gender differences, there were statistically significant differences between boys and girls. For example, more girls believed that a person is likely to be HIV?AIDS infected on having first sexual intercourse; whereas boys believed more in the use of condom, as a preventive measure against HIVIAIDS infection. Furthermore, boys believed less in the reality of HIVIAIDS than held true with girls.

Adegoke et al. (2011) comment that other studies carried out in Africa and outside Africa did not report the same 
pattern of gender differences as the Nigerian study observed. For example, males command a higher knowledge level of HIVIAIDS than is the case with females observed in Ghana and Tanzania (Ocansey 2006; Maro 2009). Bamise, Bamise \& Adedighba (2011).

Bamise, Bamise and Adedigba (2011) reported that in their study of 592 adolescents revealed that close to $50 \%$ held the belief that HIVIAIDS can be transmitted by mosquito bites; $53.7 \%$ believed that HIVIAIDS can be transmitted by kissing; 92.4\% said they had heard about HIV AIDS; 67\% stated that HIVIAIDS was a life-threatening disease; $29.4 \%$ argued that there is a cure for HIVIAIDS. Moreover, this study revealed a high level of misconceptions among secondary school students (Bamise et al. 2011). Gender differences between girls and boys were such that females were more knowledgeable than males in a ratio of $52.3 \%$ t0 $47.7 \%$. This kind of finding was replicated in a study carried out by Aylike et al. (2013) in Turkey with the objective of assessing HIVIAIDS knowledge among high school students. It was based on a sample of 230 boys and 243 girls with a mean age of 16.5 .

The end results showed that girls were statistically more knowledgeable than boys particularly in the following aspects: HIVIAIDS prevention and treatment. This is noted as being in contrast with research carried out in Kenya, Zimbabwe and Scandinavia countries where it was observed that both girls and boys were at parity in their level of HIVIAIDS knowledge (Eriksson, Sonesson \& Isasson 1997).

In Ethiopia, Oljira, Berhane, \& Worku (2013) made assessment of comprehensive HI/AIDS knowledge level among in-school adolescents. The results showed that in a sample of 2766 of respondents, one in four adolescents (24.5\%) had a comprehensive knowledge of HIVIAIDS. It was particularly noticed that boys had a higher level of comprehensive knowledge than their counterparts the girls. Girls were more vulnerable to HIVIAIDS than the boys. Of those invited for participate in the investigation, the success rate for boys was $27.3 \%$ compared to a score of $17.3 \%$ for girls.

On the other hand, Gupta et al. (2013) studied American secondary school students', 113 girls and 102 boys, HIVIAIDS knowledge and did not observe any gender differences that reached a significant level statistically. While this was so. This was further confirmed by a Nigerian study on gender differences in students' knowledge of HIVIAIDS in the Niger Delta. While there was no gender differences, there was evidence that girls performed better in some of the questions based on their responses.

Ayopo (2009) made a study of Nigerian adolescent students' perceptions of HIVIAIDS and their attitudes to prevention methods. The results were that the adolescents showed that they had positive perceptions and attitudes toward HIVIAIDS, and that they were also familiar with methods used for guarding against contracting HIVIAIDS. Along a similar line, Durojaiye (2009) explored the Nigerian youth knowledge, perception and behaviour and practice in the City of Lagos. Their level of knowledge of HIVIAIDS stood at 8.3 out of 10 points. Close to $73.5 \%$ did not believe that they were at risk of contracting HIVIAEDS, though $70.3 \%$ had multiple sexual partners. However, those who thought there was possibility of contracting HIVIAIDS made use of condom on a regular basis. With those who had low perception of contracting HIVIAIDS, there was no commitment to behaviour change.

Singh and Jain (2009) in India studied secondary school adolescents' awareness of HIVIAIDS in the District of Gujarat. The sample comprised 755 participants drawn from 29 schools. Over $90 \%$ were familiar with the various ways HVIAIDS is transmitted, and over $80 \%$ were familiar with various ways of guarding against its infection.

Most participants were familiar with the knowledge that, there is no cure for HIVIAIDS. There were also a few misconceptions reported that, HIV could be contracted as a result of mosquito bite and casual contact. Singh and Jain (2009) concluded their investigation by pointing out that, sex education that includes HIVIAIDS would contribute to the lowering of HIVIAIDS transmission. This is particularly so for African adolescents.

On the other hand, Lenono (2007) made a study of Love life counsellors' perception of the impact of HIV'IAIDS on the sexual conduct of adolescents. The study aimed at examining the extent to which love life counsellors were of the view that Love life had had an impact on adolescents' sexual activity, and whether adolescents expressed their sexuality differently, as a result of HIVIAIDS. The study further investigated counsellors' perception of adolescents' use of condoms, being faithful to one partner and abstaining.

It was the view of the counsellors that adolescents had a change in their expression of sexuality, as a result of their awareness of HIVIAIDS. Such a change manifested itself by reduction in the adolescents' contracting HIVIAIDS. HIVIAIDs had impact on how adolescents conducted themselves sexually. Adolescents take seriously the danger of HIVIAIDS to one's life. Furthermore, they are adhering to the three principles of CBA standing for use of condom, be faithful and abstain. It was nevertheless noted that many adolescents find it rather difficult to abstain from sex altogether.

According to Naswa and Marfatia (2010), an adolescent contracts HIV and remains infected and affecting others, so long as he/she lives. This is particularly so, as a result of the prolonged duration as a result of medical treatment, particularly by means of anti-retroviral. It was estimated that $36 \%$ male and $20 \%$ female had a comprehensive knowledge of HIVIAIDS. Comparatively, rural adolescents knew less about HIV than adolescents in rural areas. 
It has been reported frequently that, women are more likely to contract HIV than is the case with men (Phiri, 2004; Denis, 2003; Clifford, 2004). Denis (2003) asserts that HIVIAIDS is a gender issue given that marriage is instrumental in contracting HIVIAIDS. Among adolescents of 15-24 years, girls are five times more likely to be infected more than the boys. Married women contract HIVIAIDS more than any other group in the population. According to Clifford (2004), women constitute $50 \%$ of all people suffering from HIVIAIDS globally. Some of the reasons for women being more vulnerable than other groups in the populations are as follows: poverty, need to provide for children. At risk of abuse, lack of option for negotiating safe sex, culturally discriminated, hormonal changes, vaginal microbial ecology and physiology and higher presence of sexually transmitted diseases.

Burgoya and Drumond (2008) report that comparatively, women in Africa are more affected with HIVIAIDS than is the case with their counterpart the men. The reasons for such gender difference are many and are as follows: poorly educated, those with rural background, those who are economically dependent on men; taboo imposed on them by their culture regarding discussion based on sexual matters and health, submissive aspect in relationship with men; men dominant role in sexual decision making. All these factors contribute to women being less informed about HIVIAIDS. Hence, making them more susceptible to HIVIAIDS infection.

According to Gahagan (2012) her investigation in Canada indicates that there is an increase in the number of women contracting HIVIAIDS which constitutes the reason for further investigation into gender inequality in the contraction of HIVIAIDS. She goes on point out many societies place the gender role of women in a position which makes it rather difficult for women to protect themselves against HIVIAIDS transmission. For examples, making it difficult to practice safer sex and being unable to avail themselves with HIV prevention services; women have less access to education, income, employment. In the long run these hold the women's limitations in their negotiation for safe sex and access to prevention to available prevention services

Terry, Mhloys, Masavaure and Adlis (2005) investigated gender differences in HIVIAIDS knowledge among 933 university students in Zimbabwe on the basis of cultural, sociological and economic variables. Male participants expressed the views that: they had the right to dominate women, and that they were the ones to decide the use of condom. In contrast, the women participants acknowledged the gender cultural attitude towards women and went further by asserting their support for women's rights to sexual activity.

In a similar investigation, Ugbona, Kooffeh and Nwauche (2011) examined gender differences in students' knowledge of HIVIAIDS on a sample of 1748 secondary school students aged 12-19 years of ge drawn from 12 schools. Their knowledge was high as it stood at $80 \%$. However, there was no gender difference in their knowledge of HIVIAIDS

Montosh, Asagwara and Meriamu (2011) carried out a study of 2399 university students in Lagos, Nigeria, in which participants had a moderate knowledge of HIVIAIDS. It was also reported that female participants were predisposed to contracting HIVIAIDS, because of their engaging in high risk sexual behaviour for financial reasons. In terms of gender difference in HIVIAIDS, no difference of significance was observed.

According to a cross-national survey carried out in Ethiopia, Mali and Nigeria $97-98 \%$ of men had a knowledge of HIVIAIDS compared to $86-90 \%$ for women who were just as knowledgeable. Similar survey carried out in Kenya and Madagascar showed gender difference showing that men showed more than women. The study carried out in Rwanda, however, showed no gender difference in HIVIAIDS between females and males.

Durojaiye (2011) refers to HIVIAIDS is one of the most dreaded and devastating diseases in human recent history. It is therefore argued that behaviour change on the part of men and women presents the most effective way of controlling transmission and infection of HIVIAIDS. In a sample of 315 students consisting of both married and single participants. Their knowledge of HIVIAIDS was very high. It was observed that participants who were married were more knowledgeable than those who were single. On the other hand, a statistical analysis the gender differences between male and female participants were on-significant.

In Malysia, Wong, Chin, Low and Jaafar (2008) young adults knowledge of HIVIAIDS was moderate given that they had of 4.6 out of 17 points. The majority of participants knew what HIVIAIDS was about. There were gender differences with female participants showing higher scores than male participants. Mundingayi, Lutala and Mupenda (2011) in Kinshasha, Deomcratic Republic of Congo, advance the argument that knowledge has a prominent role as predictor of HIV risk behaviour. As a result of IVIAIDS knowledge, the following are likely to hold true: deferred onset of sexual relationship; consistent use of preventive measures during sexual intercourse; reduction in the number of sexual partners; increase in relating to HIVIAIDS infected persons positively. Their investigation of HIVIAIDS knowledge was high for both female and male participants. As such, there was no gender difference.

The preceding review of literature and their various arguments informed the present investigation of gender differences in HIVIAIDS knowledge among high school adolescents in Kenya. 


\section{Method}

\subsection{Sample}

The sample of this study was based on 157 high school students comprising 88 boys and 69 girls. Their age ranged from 16-18 years with a mean of 17 years. The participants were selected from two randomly identified high schools in the City of Nairobi, Kenya. Participants were multilingual, as they spoke different ethnic languages spoken in Kenya. Their understanding of the English language used in the questionnaire was good. For the purpose of confidentiality, participants were not asked for their names or name of the school they were attending. They were, however, asked to indicate their gender and date of birth.

\subsection{Instrument}

A nineteen-statements/questions questionnaire on their knowledge of HIVIAIDS was administered for their responses. The questionnaire addressed issues related to the transmission, infection and prevention of HIVIAIDS.

For each statement on HIVIAIDS there were three answers from which the participants were to tick the most appropriate response as applied to their knowledge of HIVIAIDS. The options were "Yes, No, Do not know".

\subsection{Procedure}

Two academics at the University of Nairobi were responsible for the collection of data. Permission to administer the HIVIAIDS questionnaire was sought from the Senior Management of the selected Schools. Following their consent, the questionnaire was administered after briefing the participants that, the questionnaire was to find out how much they knew about HIVIAIDS, and that their participation was subject to their being agreeable to doing so. They all agreed to participate. They were given 15-20 minutes to complete the questionnaire.

\subsection{Data Analysis}

Two statistical analysis were used for the purposes of determining the participants' gender differences in their knowledge about HIVIAIDS. The first approach was to examine the frequencies in terms of the responses made to the questionnaire. These were converted into percentages on the assumption that, the higher the percentage was a reflection of how well informed the participants were about HIVIAIDS.. The second analysis was based on a $2 \times 2$ chi-square contingency Table. Whether responses were statistically significant was dependent on whether the gender chi-square means difference was statistically significant.

\section{Results}

Table 1 shows the results based on: frequencies, percentage, chi-square and the level of probability. There was a gender difference response as to whether one would contract HI/AIDS as a result of sharing a cigarette with an HIVIAIDS infected person. More girls performed better than boys. In terms of $X^{2}$ (1df, N156) $=4.54 p<0.05$ was statistically significant When asked whether drinking from a glass used by an infected person would lead to contracting HIVIAIDS, there was no gender difference, meaning that both genders performed equally well.. There was gender difference concerning, the sharing of food with an HIVIAIDS person. Girls scored higher than the boys, as confirmed by the chisquare contingency Table $\chi^{2}(1 \mathrm{df}, \mathrm{N} 156)=3.21, \mathrm{p}<0.10$. There was no gender difference in use of a common toilet seat as source of HIVIAIDS, as one of the ways of being infected with HIVIAIDS. As regards kissing a person who is HIVIAIDS, as source of infection was rejected by more boys than girls. The gender difference was statistically significant, $X^{2}$ ( $1 d f$, $N 156)=31.25, p<0.00$ 
Table 1: Participants' Correct Responses, Frequencies, Percentage, Chi-squares and Probability

\section{$\mathrm{N}=157$}

\begin{tabular}{|c|l|c|c|c|c|c|c|}
\hline \multirow{2}{*}{ No. } & \multirow{2}{*}{ Statement } & \multicolumn{2}{|c|}{ Males } & \multicolumn{2}{|c|}{ Females } & & \\
\cline { 3 - 7 } & & Freq. & $\%$ & Freq. & $\%$ & $\mathbf{X}^{2}$ & $\mathbf{P}$ \\
\hline 2 & Sharing cigarette with AIDS person & 85 & 85 & 60 & 87 & 4.54 & 0.05 \\
\hline 3 & Sharing a cup with AIDS person & 87 & 87 & 60 & 87 & 4.91 & 0.05 \\
\hline 4 & Sharing food with infected person & 87 & 87 & 65 & 94 & 3.21 & 0.10 \\
\hline 5 & Using same toilet seat AIDS person & 78 & 78 & 53 & 79 & 0.08 & $\mathrm{~ns}$ \\
\hline 6 & Kissing an AIDS person & 74 & 84 & 29 & 42 & 31.25 & 0.001 \\
\hline 7 & Taking care of AIDS person & 58 & 66 & 61 & 88 & 57.9 & 0.001 \\
\hline 9 & Sharing clothes with AIDS person & 97 & 90 & 61 & 88 & 3.9 & 0.05 \\
\hline 10 & Blood transfusion from AIDS person & 81 & 92 & 69 & 100 & 1.2 & $\mathrm{~ns}$ \\
\hline 11 & Having sex an infected person & 82 & 91 & 69 & 100 & 1.22 & $\mathrm{~ns}$ \\
\hline 12 & Shaking hands with AIDS person & 82 & 93 & 67 & 97 & 1.8 & $\mathrm{~ns}$ \\
\hline 13 & Mosquito bite & 33 & 43 & 57 & 82 & 26.8 & 0.001 \\
\hline 14 & There is no cure for AIDS & 58 & 66 & 60 & 87 & 9.8 & 0.01 \\
\hline 16 & AlDS is punishment for engaging in sex outside marriage & 50 & 57 & 28 & 41 & 0.95 & $\mathrm{~ns}$ \\
\hline 17 & AlDS persons should be avoided & 37 & 42 & 62 & 90 & 25.4 & 0.001 \\
\hline 21 & Stand a chance of & 20 & 25 & 18 & 26 & 91.6 & 0.001 \\
\hline 21 & Contracting AIDS? & & & & & & \\
\hline
\end{tabular}

\begin{tabular}{|c|l|c|c|c|c|c|c|}
\hline \multirow{2}{*}{ No. } & \multirow{2}{*}{ Statement } & \multicolumn{3}{|c|}{} & \multicolumn{3}{|c|}{} \\
\cline { 3 - 8 } & & Freq. & $\%$ & Freq. & $\%$ & $\mathbf{X}^{2}$ & P \\
\hline 22 & Careful in relationship with gender counterpart to avoid AIDS & 85 & 97 & 65 & 84 & 2.9 & 0.10 \\
\hline 23 & Should AIDS children be in the same school with those who do not have & 57 & 65 & 57 & 82 & 11.8 & 0.01 \\
\hline 24 & AIDS? & 36 & 40 & 35 & 57 & 54 & 0.001 \\
\hline 25 & Would you sleep with an AIDS person? & 80 & 91 & 58 & 84 & 5.43 & 0.05 \\
\hline
\end{tabular}

Taking care of an infected person as one of the ways HIVIAIDS can be transmitted was rejected by more girls than boys. Calculation of $X^{2}$ (1df. N156) $=57.9, p<0.001$ was significant.

There is a belief that, one can contract HIVIAIDS by sharing clothes with an infected person. There was gender difference as boys scored higher than girls; $X^{2}(1 \mathrm{df}, \mathrm{N} 156)=3.9, p<0.05$ Getting blood transfusion from an infected person was equally accepted as a correct narration by both girls and boys. As such, there was no gender difference. The same held true for engaging in sexual behaviour with a person who is infected which was equally accepted in equal proportion by both girls and boys. Shaking hands with an infected person was not considered a source of transmission by both girls and boys, and therefore, there was no gender difference as such. Mosquito bites were not considered as instrumental to being infected by more girls than boys. Chi-square for those who reflected the role of mosquito in HIVIAIDS was $\chi^{2}$ (1df, N156) $=26.8, p<0.001$ Whether there is a cure for HIVIAIDS, there was gender difference as more girls performed better than boys. The rejection of the statement was $x^{2}(1 \mathrm{df}, \mathrm{N156})=9.8, p<0.01$ The belief that HIVIAIDS is God's punishment, for engaging in sex out of wedlock, was rejected in equal proportion by both genders. Avoidance of those who are infected, the gender difference was $x^{2}(1 \mathrm{df}, \mathrm{N} 156)=25.4, p<0.001$ with girls outscoring boys. The chance of contracting HIVIAIDS was denied by more girls than boys. The chi-square in terms of denial was $X^{2}(1 \mathrm{df}, \mathrm{N} 156)=91.6, P<0.001$

For the purpose of exploring the transfer of knowledge to sexual behaviour, participants responded to the question of whether there were attempts on their part to avoid having relationship with girls or boys for fear of HIVIAIDS transmission. There was a slight gender difference, with boys being more careful than girls; $\chi^{2}(1 d f, N 156)=2.9, p<0.10$. In response to the question of whether HIVIAIDS children should attend school with uninfected children, there was gender difference, with more girls supporting the statement than the number of boys; $X^{2}(1 \mathrm{df}, N 156)=11.8, p<0.01$. Whether one would share a bed with an HIVIAIDS person, the response indicated gender difference with girls expressing that there would be no problem doing so. Sharing a bed with an infected person was $X^{2}$ (1df, N156)=54, $p<0.001$. A considerable proportion of respondents would not be prepared to do so.

The last question sought to find out whether, participants would be feel comfortable sitting next to an HIVIAIDS person. The response showed a gender difference in favour of boys who said they would have no problem doing so. Those agreeable sitting next to an HIVIAIDS person, $X^{2}(1 \mathrm{df}, N 156)=5.43, p<0.05$ which was statistically significant. 
In summary, the results of the data analyses show three types of results, namely: there is no gender difference; there is gender difference; and where there is difference, either boys or girls are more knowledgeable than their counterpart. Such results are reflective of what other researchers have reported in the literature review.

\section{Discussion}

In Kenya by December 2011, there were 1.6 million Kenyans living with HIVIAIDS. Consequently, HIVIAIDS continues being the greatest challenge Kenyans are faced with. Those affected and infected most are girls and women; there are $59 \%$ women and girls living with HIVIAIDS. Such backdrop informed the investigation of gender differences in the knowledge of HIVIAIDS among Kenyan high school students. Such knowledge on the part of young Kenyans would contribute measurably to the combat and prevention of HIVIAIDS. In as much as HIVIAIDS is not curable, prevention through public education remains the only surety for combating the epidemic.

While there have been numerous studies of adolescents regarding the level of their HIVIAIDS knowledge, there have been rather few studying gender differences, which is one of the reasons for the pursuit of the present investigation.

One could interpret the present investigation of dual objectives consisting of a major and minor objectives. The major objective was to investigate gender differences in the level of HIVIAIDS knowledge between high school girls and boys in the city of Nairobi Kenya. Specifically which one of the genders has a significantly higher level of HIVIAIDS knowledge. Would such level of HIVIAIDS to the entire battery of the questionnaire or would it be selectively different. The minor aspect of the dual objectives was to establish whether both groups of participants would generally command a high level of HIVIAIDS knowledge similar to what has been reported in the HIVIAIDS.

Based on the analyses of data, there were diverse responses that divided the respondents into three major categories. There was the parity category in which both girls and boys performed equally well. The second category consisted of boys outperforming girls in their HIVIAIDS knowledge. The third category comprised girls whose HIVIAIDS knowledge was higher than that of their counterparts. Such diversity in categories is also reflected in what other researchers have observed from time to time in the recent past.

In the parity category, there were no gender differences in believing that sharing same toilet seat. Second, there was no gender difference in rejecting the fact that donating blood would lead to being HIVIAIDS infected. Third, both genders did not go along with engaging in sexual activity with an HIVIAIDS person and not contracting HIVIAIDS as a consequence. Furthermore, the parity category took the same position in rejecting or accepting statements/questions regarding: shaking hands with an HIVAIDS infected person; mosquito bites leading to HIVIAIDS transmission; both genders did subscribe to the belief that HIVIAIDS is God's way punishing those who engage in sexual immorality. There was no gender difference in rejecting the practice of shaking hands with an HIVIAIDS infected person, as one of the ways one can contract HIVIAIDS. In the category of boys performing better than girls, the following held true in response to the questionnaire: First boys had more HIVIAIDS knowledge that, one would not be infected as a result of exchanging a kiss with an HIVIAIDS infected person. Regarding sharing clothes with an HIVIAIDS person leading to the transmission of infection. Being more careful in relating to members of the opposite sex, boys were more careful than was the case with girls. Similarly, boys did not think that by sitting next to an infected person would lead to being infected with HIVIAIDS.

On the third category where gender differences were observed with girls performing better than boys, the observation was as follows: Sharing a cigarette leading HIVIAIDS leading to the transmission, boys had more knowledge than girls. The same held true for sharing food with an infected person. The gender difference in terms of taking a an HIVIAIDS infected person, girls had more knowledge than their counterparts. The gender differences in avoiding taking care of people who live with aids; girls had more knowledge than others did. Girls scored more than boys in the possibility of ever being HIVIAIDS positive.

The results of this investigation are in line with the expression one size fits all in so far as the results have an answer for each one of them. For example, partially, the hypothesis that girls are more informed in the HIVIAIDS knowledge has been confirmed in a number of responses to some of the questions. Similarly, in the case of boys' performance some of the responses show that boys are more knowledgeable. In the third category where no gender differences were observed was similarly confirmed.

In the category of girls being in greater proportion regarding HIVIAIDS knowledge, various investigations have confirmed such findings. For example, Ayiike et al. (2013) assessed HIVIAIDS knowledge among high school students in Turkey comprising 230 boys and 243 girls whose ages were a mean of 16.5 . Girls were statistically more knowledgeable than boys particularly in the following: HIVIAIDS prevention and treatment Celick et al. (2007) in Turkey, had a sample of 898 participants with a breakdown of 227 women and 671 men aimed at finding out HIVIAIDS knowledge of internet users, given that internet is frequently used as a means of securing information, engaging in conversation and search for 
sexual partners. To obtain such information, a standard web-based questionnaire was administered. Women were found to be more HIVIAIDS informed than men.

Further examination of the third category shows the majority of responses fell under this category, thus lending support to the conclusion that perhaps, there are no gender difference in the HIVIAIDS that both boys and girls are in possession of. It would follow that this has had support from various previous research findings. For example, Ugboma et al. (2011) in their assessment of HIVIAIDS knowledge among Niger Delta, Nigeria school adolescents, there was no gender difference, even though in some of the questions either boys or girls performed better. Similarly, Gupta et al (2013) reported no gender difference among secondary school students. In a Nairobi, Kenya based study, Kabiru \& Orpinas (2009) reported that there was no significant difference between boys and girls in their knowledge of HIVIAIDS. Eriksson \& Somessons \& Isasson (1997) observed that in Kenya, Zinbabwe and Scandivavian countries, both boys and girls were at parity in their level of HIVIAIDS knowledge. In Iran, Sohail et al. (2011) made a study of 600 high school students and concluded that their knowledge of HIVIAIDS was of moderate level knowledge, there was no significant gender difference. To the extent that in the present investigation there was no gender differences for the parity category, it contradicts what some Kenyan studies have observed that girls and women are less knowledgeable than boys and men (NACC \& NASCOP 2012; Mwendwa 2013)

In the category of boys being more knowledge in HIVIAIDS knowledge has support from various researchers. For example, Oljira et al. (2013) assessed knowledge of adolescents in what was referred to as comprehensive knowledge of HIVIAIDS in a sample of 677 . The results showed that boys had a higher level of comprehensive knowledge than their counterparts, the girls; and that female participants were more vulnerable to HIVIAIDS than the males.

\section{Summary}

It has been reported frequently that, women are more likely to contract HIV than is the case with men (Phiri, 2004; Denis, 2003; Clifford, 2004). Denis (2003) asserts that HIVIAIDS is a gender issue given that marriage is instrumental in contracting HIVIAIDS. Among adolescents of 15-24 years, girls are five times more likely to be infected more than the boys. Married women contract HIVIAIDS more than any other group in the population. According to Clifford (2004), women constitute $50 \%$ of all people suffering from HIVIAIDS globally. Some of the reasons for women being more vulnerable than other groups in the populations are as follows: poverty, need to provide for children. At risk of abuse, lack of option for negotiating safe sex, culturally discriminated, hormonal changes, vaginal microbial ecology and physiology and higher presence of sexually transmitted diseases.

Burgoya and Drumond (2008) report that comparatively, women in Africa are more affected with HIVIAIDS than is the case with their counterpart the men. The reasons for such gender difference are many and are as follows: poorly educated, those with rural background, those who are economically dependent on men; taboo imposed on them by their culture regarding discussion based on sexual matters and health, submissive aspect in relationship with men; men dominant role in sexual decision making. All these factors contribute to women being less informed about HIVIAIDS. Hence, making them more susceptible to HIVIAIDS infection.

\section{Conclusion}

The purpose of this investigation was of dual nature in that it wanted to confirm or dis disconfirm the level of HIVIAIDS knowledge among high school students in Kenya. Second, the investigation aimed at exploring whether the HIVIAIDS knowledge adolescents would differ on gender lines. Both objectives were confirmed by the findings.

There were three types of responses emanating from respondents. The majority indicated that both male and female participants were at par in their knowledge regarding HIVIAIDS level of knowledge. Equally true, there were questions where it was shown that boys were more knowledgeable than girls. The converse also held true for girls where girls were more knowledgeable than boys.

In view of the fact that, HIVIAIDS has no known cure, there is need for comprehensive sexuality education programmes which will equip adolescents to protect themselves against the scourge of HIV/AIDS. In short, what is being advocated is educating, motivating, persuading and enabling should be the chief cornerstones of HIVIAIDS public education campaigns.

\section{References}

African Population and Health Research Center (2009) Policy brief: Protecting in-school adolescents from HIVIAIDS, STI and unwanted 
pregnancy. Online at: www.realising.rights.org/docs/newsletter/adolescents policy brief final pdf (2)pdf [Accessed 20 April 2012]

Ayiike BU, Bamise CT, Hamid MM, Turkal \& Colak H (2013) HIVIAIDS knowledge among high scool students in Kirikkale province, Turkey. Journal of Natural; science, Biology and Medicine, 4(1), 81-86.

Ayopo J. M. (2007) Exploring Nigerian adolescent students perceptions of HIVIAIDS and their attitudes to prevention methods: A psycho of educational perspective. Online at: http:/hdl.handle.net/10500/3039nal pdf (2) pdf [Accessed 15 May 2012]

Burgoya A. D. And Drummond P. (2008). Knowledge of HIV and AIDS in women in Sub-Saharan Africa. African Journal of Reproductive Health, 12(2), 14-31.

Celik M, Arican O \& Celikoz-Ozkan D (2007) Turkish internet users awareness of and attitudes towards HIVIAIDS and other STDs. Acta Dermatoven APA, 26(1)

Clifford P. (2004). Theology and the HIVIAIDS epidemic. Online at: $w w w$

.christianmail.org-uk/images/hiv-theologyfinals.pdf.

Denis P. (2003). Sexuality and AIDS in South Africa. Journal of Theology for Southern Africa, 115, 75.

Durojaiye O. (2011). Knowledge, attitude and practice of HICVIAIDS: Behavior change among tertiary education students in Lagos, Nigeria. Annals of Tropical Medicine and Public Health, 41(1), 18-24

Durojaiye C. O. (2009) Knowledge, perception and behaviour of Nigerian youths on HIVIAIDS. The Internet Journal of Health, 9(1)

Ericksson T., Sonesson A. \& Isacsson A. (1997) HIVIAIDS information and knowledge: A comparative study of Kenyan and Swedish teenagers. Scandinavian Journal of Public Health, 25(2), 111-118.

Facente A. (2001) Adolescents and HIV: knowledge, behaviours, influences, and risk perceptions. The Journal of School Nursing, 17(4), 198-203.

Gahagan J. (2012). Gender matters in HIV prevention. Online at:www.catie.ca/en/pf/spring-2012/gender matters-hiv-prevention

Gakahu N \& Kaguta J (2011) Communicating HIV \& AIDS among students in Kenya' institutions of higher learing: A challenge for the $21^{\text {st }}$ century. Journal of Economics and Sustainable Development, 2(4)

Gupta P, Anyum F, Bhardway P, Srivastay JP \& Zaidi ZH (2013) Knowledge about HIVIAIDS among secondary school students. Northern AmericanJournal of Medical Science, 5(2), 119-123)

Jankie D., Garegae K. \& Tshako G. (2011) Using focus group interviews to research adolescents' beliefs and perceptions of sex, sexuality, HIV and AIDS in educational settings: Methodological successes and challenges. International Journal of scientific Research in Education 4(2), 131-141

Njogu W \& Martin T.C. (2003). The persisting gap between HIVIAIDS knowledge and perception among Kenyan youth. GENUS, 62(2), 135-168

Kabiru W. \& Orpinas P. (2009a). Factors associated with sexual activity among high school students in Nairobi, Kenya. Journal of Adolescence 32(4), 1023-1039

Kabiru C. W. \& Orpinas P. (2009b) Correlates of condom use among male high school students in Nairobi, Kenya. Journal of School Health 29(9), 425-432.

Kamala B. A. \& Aboud S. (2006) Knowledge, attitudes and practices on HIV prevention among secondary school students in Bukoba rural, Kagera Region,_Tanzania. Dar es Salaam Medical Students Health Journal, 14(1), 14-18

Kibombo R., Neema S. \& Ahmed F. (2007) Adolescents and their perceptions of HIVIAIDS. African Journal of Reproductive Health, 11(3), 168-181

Lenono P. R. (2007) Lovelife counsellors' perceptions of the impact of HIV and AIDS on the sexual conduct of adolescents. Online at: http:/hdl.handle.net/10539/2202 [Accessed 10 June 2012]

Montoh S. O., Asagwara C. G. and Meriamu U. H. (2011). Male gender roles and sexuality: Implication for university girls HIVIAIDS awareness in a Nigerian university. Journal of Internatiional Women's Studies, 8(4), 148-152.

Mundingayi A., Lutala P. and Mupenda B. (2011). HIV knowledge and sexual behaviour among street adolescents in rehabilitation centres in Kishasha, DRC: Gender differences. The African Medical Journal, 10(23).

Mwamwenda TS (2014) Education level and HIVIAIDS knowledge in Kenya. Journal of AIDS and Research, 6(2), 28-32

Mwamwenda T. S. (2004) Educational Psychology: An African Perspective. Johannesburg: Heinemann

Mwendwa M (2013) HIV infected women of Loboi, Kenya: The double tragedy. The African Executive Issue 5440, 25-02, October.

National AIDS Control Council (NASCC) \& National AIDS/STI Control Programme (NASCOP) (2012). The Kenya AIDS epidemic update 2011. Nairobi: Office of the President

Naswa S. \& Marfatia Y. S. (2010) Adolescents' and HIVIAIDS. Indian Journal of Sexually Transmitted Diseases and AIDS, 31(1), 1-10

Njogu W \& Martin T.C. (2003) The persisting gap between HIVIAIDS knowledge and perception among Kenyan youth. GENUS, 62(2), 135-168

Oljira L, Berhane Y \& Worku A (2013) Assessment of comprehensive HIVIAIDS knowledge level among in-school adolescents in Eastern Ethiopia. Journal of Internal AIDS Society.

Opt S, Loffredo D, Knowlas L \& Fletcher C (2010) College Students and HIVAIDS: College Students and HIVIAIDS. A Comparison of Non-Traditional and Traditional Student Perspectives. Journal of American College Health, Volume 5 Phiri I. A. (2004). HIVIAIDS: An African theological response in mission. The Ecumenical Review, 56(4).

Summerfield L. (1990) Adolescents and AIDS. Online at: http://www.hi-ho.ne...7/refer/Summer.txt. [Accessed 25 April 2013]

Sutton MY, Hardnett FP, Wright P, Wahi S, Pathak S, Warren-Jeanpiere L \& Jones S (2011) HIVIAIDS knowledge scores and perceptions of risk among African American students attending historically Black colleges/universities. Public Health Reports 126(5), pp. 653-63. 
Sohail F, Alam GM, Khan RR \& Naem R (2011) On attitude towards HIVIAIDS among Iranian students. Pakistan Journal of Biological ciences, 13(6), 271-278.

Terry P. E. Mhloys M., Masavaure T. and Adlis S. (2005). Gender equity and HIVIAIDS prevention: Comparing gender differences in sexual practices and beliefs among Zimbabwe university students. International Quarterly of Community Helth Education, 24(1), 29-43.

Ugboma HA, Kooffreh ME \& Mwauche CA (2011) Gender differences in students' knowledge of HIVIAIDS in the Niger Delta, Nigeria. Journal of Clinical Medicine \& Research, 3(1), 20-22.

Wong L., Chin C. L., Low W. And Jaafar K. (2008). HIVIAIDS-related knowledge among Malaysian young adults: Findings from a nationwide survey. The Medscape Journal of Medicine, 10(6), 148 